\title{
Neurogenic thoracic outlet syndrome due to subclavius posticus muscle with dynamic brachial plexus compression: a case report
}

\author{
Julia Muellner ${ }^{1}$, Alain Kaelin-Lang ${ }^{2 *}$, Oliver Pfeiffer ${ }^{3}$ and Marwan Mohamed El-Koussy ${ }^{3}$
}

\begin{abstract}
Background: Neurogenic thoracic outlet syndrome is an underestimated cause of brachial weakness and pain. The subclavius posticus muscle (SPM) is an aberrant muscle originating from the medial aspect of the first rib reaching to superior border of the scapula, which may cause, depending on its activation, dynamic compression of the brachial plexus.

Case presentation: In the present study, we report about a 32-year-old male caucasian patient with weakness in radial deviation of his left hand. An isolated macrodactyly of his left middle finger had been operated twice. Electroneurography showed a carpal-tunnel-syndrome (CTS) on the left side. MRI of the brachial plexus revealed an additional muscle in the costoclavicular space, identified as SPM. To our knowledge, this is the second case report of a neurogenic thoracic outlet syndrome due to SPM, and the first case described with isolated macrodactyly and CTS in the same patient.

Conclusion: If complaints about hand weakness are only reported in cases of distinct hand positions, a dynamic compression of the brachial plexus by SPM may be the cause. A neurogenic thoracic outlet syndrome may facilitate the development of CTS.
\end{abstract}

Keywords: Neurogenic thoracic outlet syndrome, Subclavius posticus muscle, Dynamic brachial plexus compression

\section{Background}

Neurogenic thoracic outlet syndrome (NTOS) is an underestimated cause of brachial weakness, pain and sensory deficits, which is hard to diagnose. The subclavius posticus muscle (SPM) has first been described by Rosenmuller in 1800 [1]. It is an aberrant muscle originating from the medial aspect of the first rib reaching to superior border of the scapula. It may cause dynamic compression of the brachial plexus depending on its activation. Until today, only one other case of neurogenic thoracic outlet syndrome associated to SPM had been described in a patient [2]. However, post-mortal examinations show that this muscle is present in $8.9 \%$ of the individuals [3]. Furthermore, it was already shown, that

\footnotetext{
${ }^{*}$ Correspondence: alain.kaelin@eoc.ch

${ }^{2}$ Neurocenter of Southern Switzerland, Opsedale Civico, Via Tesserete 46, 6900 Lugano, Switzerland

Full list of author information is available at the end of the article
}

a neurogenic thoracic outlet syndrome may facilitate the occurrence of carpal tunnel syndrome (CTS) [4]. Here we present a case of an intermittent compression of the brachial plexus due to SPM, associated with CTS and isolated macrodactyly of the middle finger.

\section{Case presentation}

An apparently healthy 32-year-old male patient complained of reduced strength in his left hand. Over the past few months this phenomenon occurred especially and repeatedly when holding a frying pan, but there was no pain or weakness in any of the other muscles. He had two operations on his left middle finger at the ages of 10 and 18 due to a macrodactyly. Neurological examination gave evidence for a reduced sensitivity for touch in his left middle finger. In neutral position, there was no deficit of strength. Electroneurography showed mild CTS, without sign of axonal lesion of the radial nerve. In 
abduction of the left arm, there was a slight weakness in pronation, radial deviation and elevation of his left hand. Occasional fasciculations were observed in his left brachioradial muscle. Overall, we hypothesized a possible brachial plexus pathology. MRI of the left brachial plexus (Fig. 1) showed an accessory muscle, attached to the medial aspect of the first rib and superior border of the scapula near the base of the coracoid process. The muscle caused a significant narrowing of the costoclavicular space (Fig. 1b). No regular subclavius muscle could been identified on either side. Arm abduction or weight bearing would most likely accentuate the narrowing of the costoclavicular space, with subsequent compression of the brachial plexus.
Overall, NTOS with compression of the brachial plexus which increases with arm elevation and abduction was likely [5]. The muscle having this negative effect was identified as SPM which was first described by Rosenmuller [1] and was recently described in a post-mortem study of a patient suffering from Edward's syndrome [6]. In this Japanese study [3], 124 corps were examined and SPM was found to be present in 11 patients $(8.9 \%)$ and identified as a possible cause of NTOS [7]. The first case report on the presence of SPM in a live patient with NTOS was published in 2010 [2]. NTOS can trigger CTS [4], but CTS may also be associated with macrodactyly [8]. Electroneurographical changes in NTOS may be absent. Therefore, NTOS diagnose depends on clinical
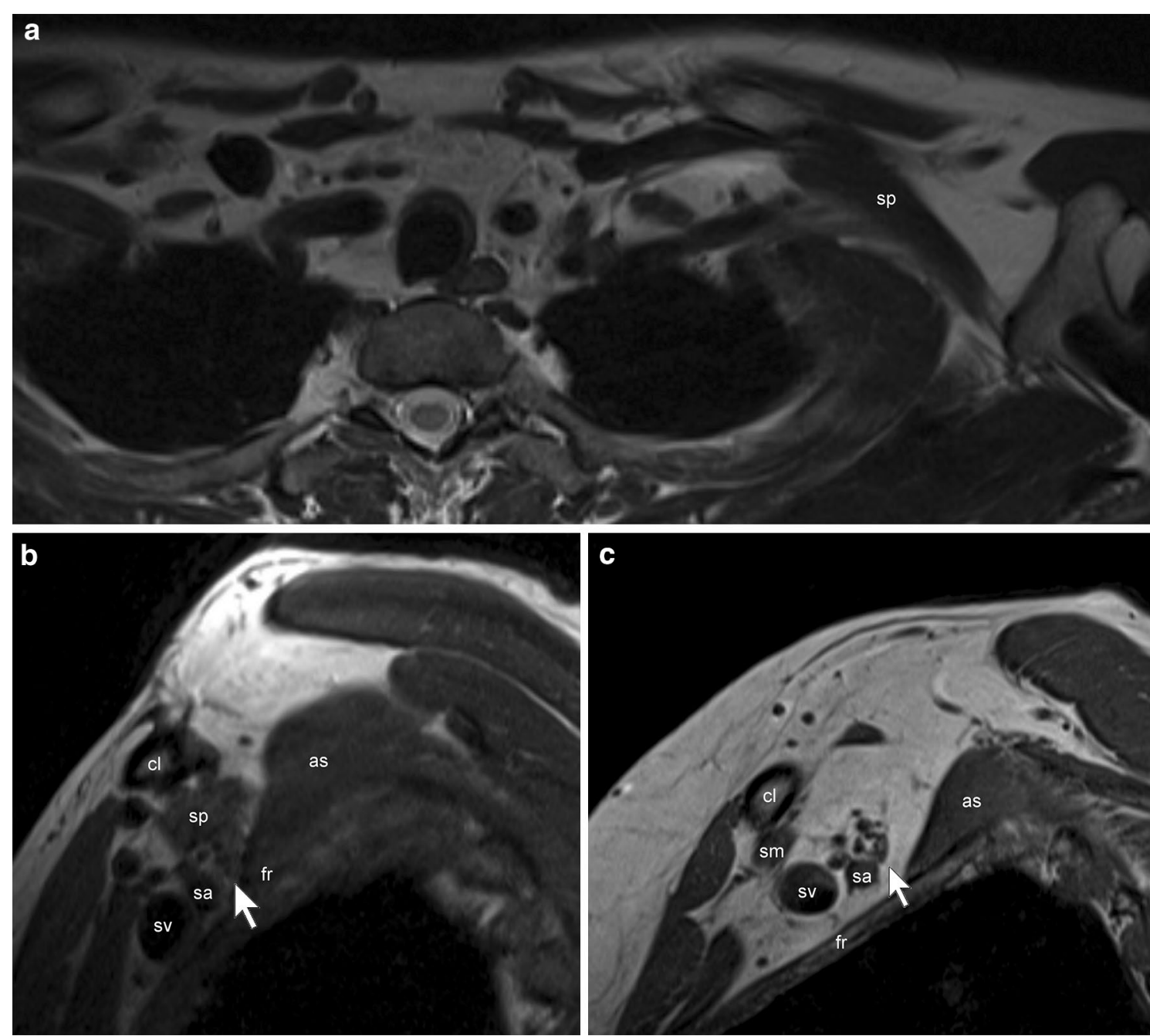

Fig. $1 \mathrm{MRl}$ of the brachial plexus at 3T (Magnetom Verio, Siemens, Erlangen, Germany), the arm adducted: a axial T2w images showed the accessory subclavius posticus muscle (sp) on the left side, attached to the superior border of the scapula and the medial aspect of the first rib ( $f r$ ). No regular subclavius muscle was found. b Sagittal T1w images showed the subclavius posticus muscle coursing over the brachial plexus (white arrow) and the subclavian artery (sa) and vein (sv), narrowing the costoclavicular space ( $c l=c l a v i c l e)$. There was only a little fat tissue left between this muscle, the neurovascular structures, the first rib and the anterior scalene muscle (as). No regular subclavius muscle was found, $\mathbf{c}$ for comparison a normal appearing costoclavicular space with a regular, thin subclavius muscle (sm) of a control subject. 
examination [9] and imaging [5]. Muscle strength should always be tested in the position in which the patient feels weaknesses or constraints, as SPM is not constantly active [2]. This is in accordance with our patient's weakness when carrying a frying pan in his left hand, whereas other muscles are at normal strength. According to a telephone interview after 6 months of the MRI examination, he reported that targeted physiotherapy over 3 months resulted in an almost full recovery and loss symptoms.

\section{Conclusion}

This case illustrates that SPM is a rare, but probably underestimated cause of NTOS. Its presence may enable the occurrence of CTS [4] as well.

\section{Consent}

Written informed consent was obtained from the patient for publication of this Case report and any accompanying images. A copy of the written consent is available for review by the Editor of this journal. The consent form signed by the patient is in accordance with the BMC research guidelines.

\section{Abbreviations}

NTOS: neurogenic thoracic outlet syndrome; SPM: subclavius posticus muscle; CTS: carpal tunnel syndrome.

\section{Authors' contributions}

Primary involved physicians and writers of the case report: JM, AK-L. Involved neuroradiologists who provided the presented image and its explanations: OP, MME-K. All authors read and approved the final manuscript.

\section{Author details}

${ }^{1}$ Department of Neurology, University Hospital Bern, Freiburgstrasse 100, 3010 Bern, Switzerland. ${ }^{2}$ Neurocenter of Southern Switzerland, Opsedale Civico, Via Tesserete 46, 6900 Lugano, Switzerland. ${ }^{3}$ Department of Neuroradiology, University Hospital Bern, Bern, Switzerland.

\section{Acknowledgements}

We thank the paramedical staff of the Department of Neurology and Neuroradiology at the University Hospital Bern who were involved in taking care of the presented patient.

\section{Compliance with ethical guidelines}

\section{Competing interests}

The authors declare that they have no competing interests.

Received: 23 March 2014 Accepted: 4 August 2015

Published online: 14 August 2015

\section{References}

1. Isenflamm HF, Rosenmüller JC (1803) Beschreibung eines doppelten Schlüsselbeinmuskels. In: Beiträge für die Zergliederungskunst, Tauchnitz, Leipzig

2. Ozçakar L, Güney MS, Ozdăg F, Alay S, Kiralp MZ, Görür R et al (2010) A sledgehammer on the brachial plexus: thoracic outlet syndrome, subclavius posticus muscle, and traction in aggregate. Arch Phys Med Rehabil 91:656-658

3. Akita K, Ibukuro K, Yamaguchi K, Heima S, Sato T (2000) The subclavius posticus muscle: a factor in arterial, venous or brachial plexus compression? Surg Radiol Anat 22:111-115

4. Vaught MS, Brismee JM, Dedrick GS, Sizer PS, Sawyer SF (2011) Association of disturbances in the thoracic outlet in subjects with carpal tunnel syndrome: a case-control study. J Hand Ther 24:44-51

5. Kim S, Choi JY, Huh YM, Song HT, Lee SA, Kim SM et al (2007) Role of magnetic resonance imaging in entrapment and compressive neuropathy-what, where, and how to see the peripheral nerves on the musculoskeletal magnetic resonance image: part 2. Upper extremity. Eur Radiol 17(2):509-522. (Epub 2006 Mar 30. Review)

6. Aziz MA (1979) Muscular and other abnormalities in a case of Edwards' syndrome (18-trisomy). Teratology 20:303-312

7. Forcada P, Rodriguez-Niedenfuhr M, Llusa M, Carrera A (2001) Subclavius posticus muscle: supernumerary muscle as a potential cause for thoracic outlet syndrome. Clin Anat 14:55-57

8. Mirza MA, King ET, Reinhart MK (1998) Carpal tunnel syndrome associated with macrodactyly. J Hand Surg Br 23:609-610

9. Braun RM (2010) Thoracic outlet syndrome: a primer on objective methods of diagnosis. J Hand Surg Am 35:1539-1541

\section{Submit your next manuscript to BioMed Central and take full advantage of:}

- Convenient online submission

- Thorough peer review

- No space constraints or color figure charges

- Immediate publication on acceptance

- Inclusion in PubMed, CAS, Scopus and Google Scholar

- Research which is freely available for redistribution

Submit your manuscript at www.biomedcentral.com/submit
() Biomed Central 